\title{
К ВОПРОСУ О БЕСКОНТАКТНЫХ ТЕХНОЛОГИЯХ ВЗАИМОДЕЙСТВИЯ И ИХ ВОЗМОЖНОСТЯХ
}

\section{ON THE ISSUE OF CONTACTLESS INTERACTION TECHNOLOGIES AND THEIR CAPABILITIES}

\section{G. Isayeva \\ N. Logacheva}

Summary. An analysis of software systems supporting modern NFC (Near Field (ommunication) technology is presented. The main characteristics of the technology, which is currently the most advanced in making payments from various devices, and the technology that can provide additional security tools along with biometrics in a wide range of areas, including the educational environment, are given. The analysis of indicators and estimates of the use of contactless electronic systems in Russia.

Keywords: contactless interaction technologies, payment applications, software system, communication, access control.

\author{
Исаева Галина Николаевна \\ К.т.н., Технологический университет, г. Королёв \\ gisaeva@ut-mo.ru \\ Логачёва Надежда Вадимовна \\ К.т.н., дочент, Технологический университет, \\ г. Королёв
}

Аннотация. Представлен анализ программных систем, поддерживающих современную технологию NFC (Near Field Communication). Даны основные характеристики технологии, являющейся на сегодняшний день передовой по осуществлению платежей с различных устройств, и технологии, которая может обеспечить дополнительные средства безопасности наряду с биометрией в широком спектре областей, в том числе и образовательной среде. Приведен анализ показателей и оценок использования бесконтактных электронных систем в России.

Ключевые слова: бесконтактные технологии взаимодействия, платежные приложения, программная система, коммуникация, контроль доступа.

с нагрузкой. Таким образом происходит пассивный обмен со стороны прослушивающего устройства.

К достоинствам рассматриваемой технологии относят скорость установки связи между устройствами: это время, менее 0,1с, а у Bluetooth это секунды. Кроме того, пассивные устройства NFC могут получать питание от полей, создаваемых активными устройствами, но с крайне малым диапазоном, что позволяет отказаться от источника питания в данных компонентах. То есть по данной технологии возможна связь с выключенным устройством. Однако, технология NFC не может обеспечить достаточно высокую индуктивность, чтобы заряжать смартфоны; но по поводу создания беспроводных зарядных устройств, базирующихся на основных принципах технологии NFC сейчас идут исследования, и будущее поколение смартфонов, возможно, уже будет заряжаться по-новому.

NFC более безопасна, чем Bluetooth или Wi-Fi. Устройства, поддерживающие данную технологию, могут и передавать, и получать данные, обеспечивая безопасность, если радиочастотное поле не соответствует связке «полученный - переданный сигнал». Электромагнитные поля могут быть использованы для передачи /получения данных от активных приемников или индуцируют электрические токи в неактивном приемном устройстве и получают от него отклик по типу «метки». И наконец, 


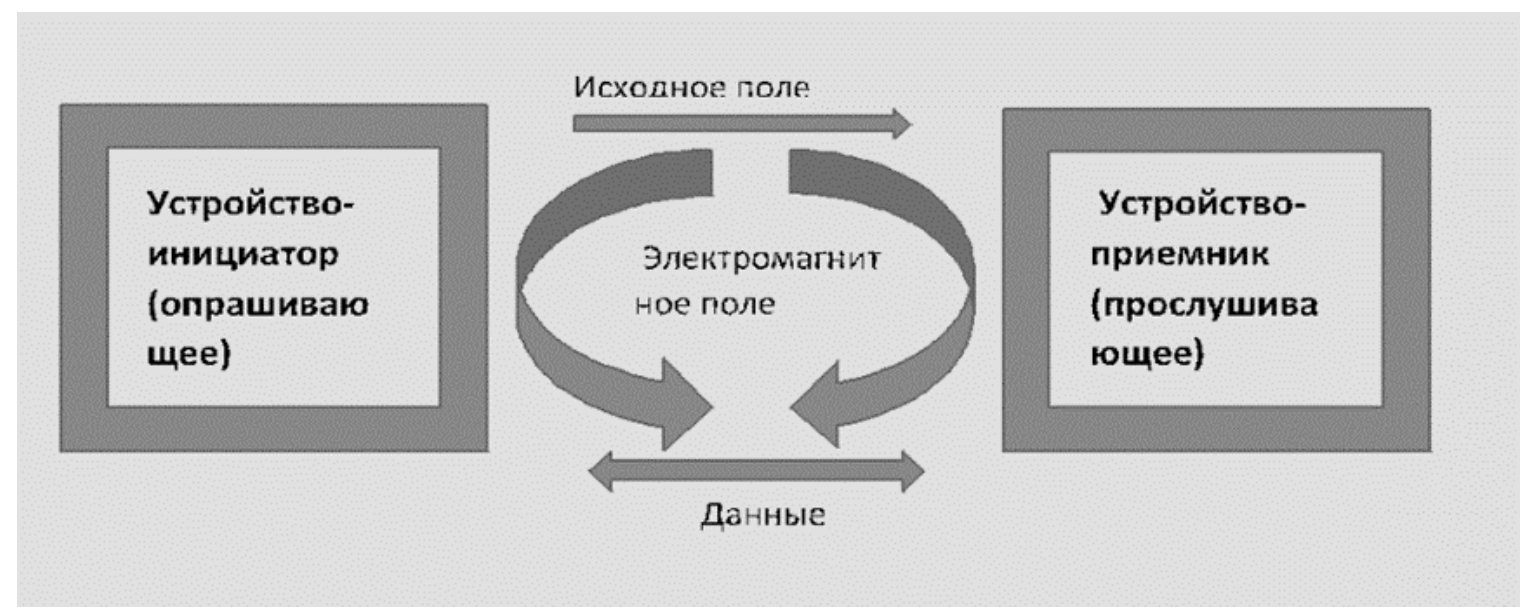

Рис. 1. Схема коммуникации устройств

устройства, в которых применима технология NFC, могут быть очень небольших размеров.

Все эти достоинства позволяют эффективно использовать смартфоны, с поддержкой технологии NFC, для выполнения различных функций пользователя. Данные устройства могут использоваться в следующих целях:

- смартфон как бесконтактная карта - эмуляция карт;

- смартфон как активное взаимодействующее устройство с пассивной NFC-меткой, (например, считывающее устройство интерактивной рекламы) - режим считывания/записи;

- смартфоны связываются и обмениваются информацией - режим P2P (peer-to-peer, равный к равному - оверлейная компьютерная сеть, базирующаяся на равноправных участниках).

Какие же программные системы обеспечивают функционал данной технологии на носимых устройствах? Нами были исследованы истоки зарождения программных платёжных систем, построенных на обсуждаемой в данной статье технологии и были рассмотрены статистические данные по результатам опросов большой выборки респондентов, владельцев носимых устройств с NFC - метками [1], [2], [8], [10].

Впервые, в России, в октябре 2016 года была представлена программная система от компании Apple, обеспечивающая мобильные платежи и электронный кошелек. Apple Pay была разработана в США в сентябре 2014 года. С помощью данной программной системы пользователи, имеющие мобильные системы iPhone версии 6 и носимые устройства Apple Watch со встроенной технологией NFC и установленным программным приложением Wallet, для хранения номеров различных социальных и финансовых «сервисов»: билетов, тало- нов, карт магазинов, кредитных карт и т.п., могли осуществлять различные бесконтактные платежи. Apple Pay вполне безопасная платежная система, в случае потери смартфона, она отключается удаленно через специальную программу, что и является гарантом для пользователя, который не понесёт денежные потери [2], [7].

Данная система поддерживается многими торговыми компаниями и магазинами во всем мире (Target, Whole Foods, McDonald's, Subway), и совместима с бесконтактными устройствами MasterCard PayPass, Visa PayWave, American Express ExpressPay, как показывают информационные источники по предоставлению услуг по производству устройств с NFC[8].

Годом позже, чем предыдуще е приложение, в Южной Корее появилась новая платежная система от фирмы Samsung Electronics, основанная на бесконтактной технологии NFC - Samsung Рay. Данная программная система позволяет осуществлять различные платежи со смартфонов семейства Samsung Galaxу и носимой техники, такой, как часы Samsung Gear. Samsung Рау, наряду c NFC-платежами, поддерживает и карты с магнитной полосой по технологии Magnetic Secure Transmission(MST) [12]. Такой подход с применением оплаты по магнитной ленте отличает эту систему от Apple Pay и Android Pay: технология MST, используя электромагнитное поле создаёт для терминала виртуальный образ карты - эмулируя настоящую банковскую платёжную карту. К приложению можно привязать до десяти карт одновременно от различных компаний и банков.

В Россию данная система пришла также пять лет назад и через, два года стала доступна держателям карт «Мир» таких банков как Альфа-Банк, «Почта банк», «Московский кредитный банк». Расширяя возможности, производители платежной системы доработали и адаптиро- 


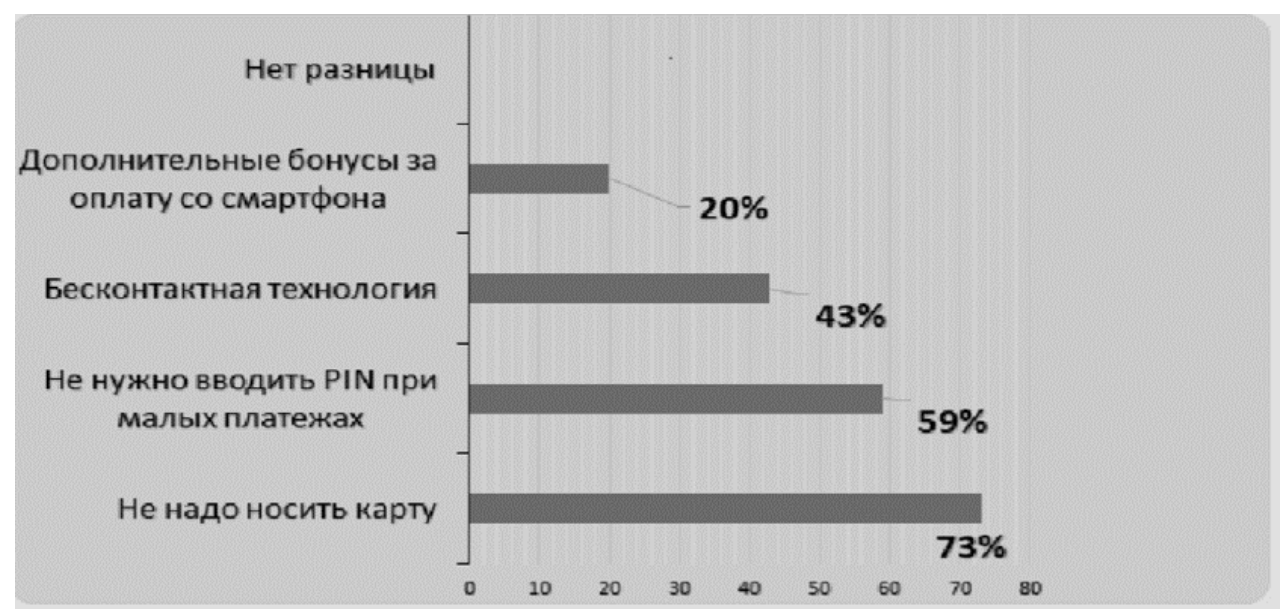

Рис. 2. Число предпочтений пользователей (\%) по отношению к носимым устройствам с NFC

вали её под телефоны, работающие под управлением операционной системы (OC) Android Lollipop (а также более поздние версии соответственно), и имеющие разрешение экрана не менее $1280 \times 720$.

Android Pay от Google с мая 2017 года вышла на мировой уровень в качестве конкурента Apple Pay и Samsung Pay. Apple Pay и Samsung Рау ориентированы на свои марки смартфонов и устройств, a Android Pay от Google предназначена для различных устройств. Приложение поддерживает платежи в браузерах Chrome, Safari и Firefox, в прикладном программном обеспечении торговых сетей KFC, «Азбука Вкуса», H\&M и других. К недостаткам можно отнести организацию системы безопасности работы приложения. Защита данных предусмотрена только на сервере компании Google, ввиду огромного количества поддерживаемых устройств и респондентов [11],[12].

С сентября 2019 года в России в тестовом режиме начали использовать смартфоны для бесконтактных платежей с установленной отечественной платёжной системой, основанной на технологии SoftPos от Промсвязьбанка. Необходимо приложить карту покупателя к личному смартфону продавца (или владельца товара) и осуществить перевод денежных средств. Использование смартфонов с NFC за короткий срок вошло в такие торгово-финансовые сферы, как малый и микро - бизнес, курьерские службы, локальные торговые точки, для которых покупка и обслуживание POS-терминала (аппаратно-программного комплекса - аналога кассового аппарата) дороги [3].

Начался новый отсчет носимых электронных устройств с NFC в организации бизнеса, культуры, обеспечения безопасности в учреждениях - различных сферах человеческой деятельности. В технических си- стемах и помещениях с секретным или ведомственным доступом, данные технологии востребованы как дополнительные средства усиления и обеспечения безопасности наряду с биометрическими технологиями. Если ранее приходилось по телефонным или другим каналам заранее согласовывать ключи доступа с разными категориями пользователей, то теперь это можно делать удалённо. Лицам, которым необходимо передать ключ, достаточно быть подключёнными к сети. Авторы видят непосредственное положительное применение носимых устройств и в сфере образования - в условиях ограничений на скопления людей и соблюдения дистанции между обучаемыми во время перерыва. В настоящее время в вузе идёт разработка мобильного приложения «Буфет МГОТУ» с возможностью он-лайн оплаты и по бесконтактной технологии.

Для такого бурного использования бесконтактной NFC-технологии есть основания: доля смартфонов с поддержкой NFC достигла половины рынка в натуральном выражении в России. По данным от компании «М. Видео-Эльдорадо» в 2019 году продажи обсуждаемых устройств выросли более, чем на 20\% в штучном измерении И второй ключевой момент - снижение средней цены смартфона с NFC на 34\%, что в денежном эквиваленте составляет около 25 тысяч рублей за устройство [3]. На конец 2020 года мировой рынок от продажи носимых устройств остановился на отметке прибыли в 30 млрд. евро - как сообщила компания Mastercard, проведя исследования популярности технологий бесконтактной оплаты при помощи носимых устройств, включая умные часы, браслеты, кольца с поддержкой NFC [2]. При опросе значимой выборки пользователей, проведённом компанией, респонденты высказались о достоинствах и предпочтениях по отношению к носимым мобильным устройствам и пластиковым картам по представленным позициям (см. рисунок 2). 
При этом наибольшей популярностью у россиян пользуется сервис Google Pay [10]. На него приходится 32\% всех совершенных бесконтактных платежей, на Apple Pay - 30\%, на Samsung Pay - 17\%. По сообщениям ТАСС 3 марта этого года, Apple Pay и Samsung Pay чаще используют в Москве и Санкт-Петербурге, a Google Рау - в других крупных городах России [8].

\section{ВывО $\Delta$}

1. Технология NFC - основа мобильных сервисов во всех сферах современной жизни. Носимые устройства и гаджеты становятся многофункциональными устройствами, объединяющими в себе аппаратные и программные средства платёжной системы, безопасности и контроля доступа, идентификации различного уровня пользователей.

2. Программные платежные системы Android Pay, Apple Pay, Samsung Pay, SoftPos наиболее популярны в России в носимых мобильных устройствах с NFC.

3. Бесконтактные технологии могут использоваться для создания комфортной среды в образовательных учреждениях в условиях соблюдения ограничений на поток обучаемых и дистанцирования между ними.

4. Большая часть респондентов - 92\%, участвующих в опросе компании Mastercard по вопросу о предпочтении мобильных сервисов, высказали мнение, что за бесконтактными мобильными устройствами - будущее [2, [1].

\section{ЛИТЕРАТУРА}

1. Бесконтактные NFC-платежи Статья 06.09.2020/ [Электронный ресурс] / код доступа: https://www.tadviser.ru/index.php/ [дата 0бращения 22.04.2021]

2. Ближняя бесконтактная связь Статья 2020/02/12 Near Field Communication (NFC) [Электронный ресурс]/ код доступа: https:// www.tadviser.ru/index.php [дата обращения 21.04.2021]

3. В России бум продаж смартфонов, поддерживающих бесконтактные платежи/ Статья 29.01.2018 [Электронный ресурс] / код доступа: https://mobilereview.com/news/v-rossii-bum-prodazh-smartfonov-podderzhivayushhix-beskontaktnye-platezh [дата обращения 21.04.2021]

4. Исаева Г.Н., Сидоров Ю.А. Использование мобильных-технологий для повышения эффективности взаимодействия программных систем - Информационно-технологический вестник».— 2019.—№ 1(19).— - . 74-80

5. Исаева Г.Н., Теодорович Н.Н. Методы обеспечения безопасности передачи данных в беспроводных сетях /Современные информационные технологии: сборник трудов по материалам 5-й всероссийской н-т конф. 27 сентября 2019 г. / под общ. ред. док. техн. наук, проф. Артюшенко В.М., док. техн. наук Воловича В.И.- М.: Издательство «Научный консультант», 2019.— - . 159-166

6. Исаева Г.Н., Теодорович Н.Н, Харламова Е.С., Польшин С.Н. Использование современных средств программирования в науке 0 данных, 一 Информационные технологии. Эволюционные процессы/ Сборник научных статей под ред.д.т.н. проф. В.М. Артюшенко, - М: Издательство «Научный консультант», $2018,-$ - c. $17-22$

7. Опасны ли оплаты покупок с помощью NFC Статья, 22.12.2020 [Электронный ресурс] /код доступа: https://www.popmech.ru/diy/527864-blizkie-kontaktykak-i-zachem-polzovatsya-nfc / [дата обращения 21.04.2021]

8. Россияне стали в три раза чаще использовать бесконтактные платежи [Электронный ресурс] 3 марта 2021/ коддоступа:https://tass.ru/ekonomika/10823013/ [дата обращения 22.04.2021]

9. Технические аспекты работы NFC Статья[Электронный ресурс]/ код доступа: https://securityrussia.com/blog/nfc.html\#4 [дата 0бращения 21.04.2021]

10. Android - руководство по NFC/ [Электронный ресурс] 23 февраля 2019/ код доступа: https://coderlessons.com/tutorials/mobilnaia-razrabotka/uchitsiaandroid/android-rukovodstvo-po-nfс [дата обращения 22.04.2021]

11. NFC — безопасность — есть ли вероятность взлома системы Статья, 15.12.2020 [Электронный ресурс] /код доступа: https://nfcwiki.ru/o-tehnologii/nfcbezopasnost.html [дата обращения 21.04.2021]

12. Samsung Pay — Больше чем просто бумажник [Электронный ресурс] /код доступа: https://www.samsung.com/ru/apps/mobile/samsungpay/ [дата обращения 21.04.2021] 